Milton Ricardo AZEDO ${ }^{1}$

Cristina de Oliveira

$\mathrm{MASSOCO}^{2}$

Maiara Garcia BLAGITZ1

Bárbara Gabriela Soares

SANCHES 1

Fernando Nogueira de

SOUZA'

Camila Freitas BATISTA ${ }^{1}$

Mônica SAKAl ${ }^{3}$

Luiz Carlos de SÁ-ROCHA ${ }^{3}$

José Roberto KFOURY

JUNIOR ${ }^{4}$

Cláudia Regina

STRICAGNOLO ${ }^{1}$

Fernando José BENESI ${ }^{1}$

Alice Maria Melville Paiva

DELLA LIBERA ${ }^{1}$

\section{Correspondência para:}

AliceMariaM. P. Della Libera-FMVZ/USP; Av. Prof. Orlando Marques de Paiva, 87, Cidade Universitária, 05508-000 São Paulo, SP

Recebido para publicação: 25/07/2007 Aprovado para publicação: 07/03/2008

\title{
Influência da leucose enzoótica bovina na função fagocítica de leucócitos circulantes em animais manifestando linfocitose persistente
}

\author{
1 - Departamento de Clínica Médica da Faculdade de Medicina Veterinária e \\ Zootecnia da Universidade de São Paulo, São Paulo-SP \\ 2 - Department of Clinical Sciences - College of Veterinary Medicine of Cornell \\ University, Ithaca, NY - USA \\ 3 - Departamento de Patologia da Faculdade de Medicina Veterinária e Zootecnia \\ da Universidade de São Paulo, São Paulo-SP \\ 4 - Departamento de Cirurgia da Faculdade de Medicina Veterinária e Zootecnia da \\ Universidade de São Paulo, São Paulo-SP
}

\section{Resumo}

Avaliou-se, por citometria de fluxo, a fagocitose de Staphylococcus aureus conjugados com iodeto de propídio (IP), por leucócitos circulantes obtidos de cinco fêmeas bovinas negativas no sorodiagnóstico para a Leucose Enzoótica Bovina (LEB); de cinco fêmeas infectadas, manifestando linfocitose persistente (LP); e de cinco fêmeas infectadas, porém alinfocitóticas. Observou-se que, entre as amostras dos animais soronegativos, a porcentagem média de células realizando fagocitose $(12,90 \%)$ não diferiu da observada entre as células dos animais alinfocitóticos $(14,70 \%)$. Contudo, ambas foram maiores $(p=0,047)$ que aquela verificada entre as células obtidas de animais manifestando LP $(7,20 \%)$. Além disso, a intensidade média de fagocitose (caracterizada pela intensidade de fluorescência do IP, em valores arbitrários), verificada em leucócitos de animais manifestando LP $(17,43)$ foi menor $(p<0,001)$ que a observada em leucócitos de animais alinfocitóticos $(29,50)$, e que a observada em leucócitos de animais soronegativos $(25,18)$, que não diferiram entre si. Assim, os resultados permitem-nos alvitrar que há alteração na função fagocítica de leucócitos circulantes em animais infectados pelo vírus da LEB, manifestando LP.

\author{
Palavras-chave: \\ Bovinos. \\ Leucócitos. \\ Fagocitose. \\ Leucose Enzoótica Bovina. \\ Citometria de fluxo.
}

\section{Introdução}

A Leucose Enzoótica Bovina (LEB), uma enfermidade neoplásica infectocontagiosa, pluri-sintomática, de evolução crônica, que afeta, particularmente, a linhagem celular linfóide destes animais ${ }^{1}$, é causada pelo vírus da leucose bovina (VLB), um deltaretrovírus relacionado aos vírus linfotrópicos de células $\mathrm{T}$ de primatas ${ }^{2,3}$. Cerca de 30 a $70 \%$ dos animais infectados pode manifestar linfocitose persistente (LP), caracterizada por uma elevação crônica no número de linfócitos circulantes e cerca de 0,1 a $10 \%$ pode desenvolver linfossarcomas em órgãos ricos em tecido linfóide, comumente os linfonodos, o baço, o coração, o útero, o abomaso, o fígado e/ou os rins, tendo ou não previamente apresentado LP. ${ }^{4}$ A infecção contribui para uma menor produção na pecuária bovina por seus efeitos danosos diretos, relacionados ao desenvolvimento tumoral, e por conseqüências indiretas. ${ }^{5,6,7,8,9,10}$

A seqüência de eventos que leva ao aumento do número de linfócitos circulantes ou ao desenvolvimento de linfossarcoma é pouco conhecida. Do mesmo modo, não está claro o efeito de tais alterações na função das células envolvidas na resposta imunológica. Por se tratar de um vírus com tropismo principal por linfócitos $\mathrm{B}^{11}$, 
investigações a propósito de uma possível imunossupressão vêm sendo feitas com ênfase em testes funcionais envolvendo, basicamente, linfócitos. Alguns estudos encerram, por sua vez, aspectos relacionados às manifestações tumorais, conquanto é suposto um caráter "benigno" e "assintomático" às outras formas de apresentação da doença. ${ }^{12}$

No entanto, diferentes populações de leucócitos apresentam papéis fundamentais na eliminação de agentes invasores através da sua fagocitose e destruição e o estudo destas funções tem importantes implicações na pesquisa de disfunções leucocitárias, no estudo da interação entre os microrganismos e o hospedeiro, na avaliação de tratamentos e de diversas condições indutoras de enfermidades em várias espécies de animais.

A avaliação da capacidade fagocítica de leucócitos pode ser feita por meio da mensuração do número de células que realizam fagocitose e do número de partículas fagocitadas por célula, utilizandose de microscopia óptica. ${ }^{13}$ Todavia, técnicas rápidas e precisas capazes de avaliar tais funções são requeridas e, neste campo, a citometria de fluxo oferece notável contribuição. A partir da fagocitose ex vivo de esferas de látex fluorescentes ou de bactérias ou leveduras conjugadas com marcadores fluorescentes, esta técnica permite a observação da proporção de células realizando fagocitose, bem como de sua intensidade. Além disso, tal metodologia mostra-se célere, necessitando de uma menor quantidade de células e dispensando a prévia separação das populações leucocitárias. ${ }^{14,15}$

Contudo, poucos estudos foram realizados avaliando-se a função fagocítica de leucócitos de bovinos, empregando citometria de fluxo ${ }^{16,17,18}$, não obstante a ampla variedade de métodos para avaliar a fagocitose e o metabolismo oxidativo de células humanas ${ }^{19,20}$, já empregados, também, para a avaliação da resposta imune de eqüinos ${ }^{21,22}$. Ainda, até onde se pôde verificar, não há relatos acerca da avaliação da influência da infecção pelo VLB na capacidade fagocítica de leucócitos.

Neste escopo, o presente trabalho buscou avaliar a fagocitose in vitro de Staphylococcus aureus conjugados com Iodeto de Propídio (Sa-IP) por leucócitos circulantes obtidos de fêmeas bovinas negativas no diagnóstico para LEB e de fêmeas bovinas naturalmente infectadas pelo VLB, alinfocitóticas e manifestando LP, como medida da possível alteração imunológica decorrente da LEB.

\section{Material e Métodos}

Foram triadas 99 fêmeas bovinas adultas em lactação, com idade variando entre 30 e 72 meses, da raça Holandês Preto e Branco, oriundas de um único rebanho, apresentando bom estado nutricional, que não haviam sido submetidas a tratamento com glicocorticóides nos últimos 30 dias, assim como não se encontravam em fase puerperal.

As fêmeas foram classificadas segundo os resultados do teste de Imunodifusão em Agar Gel para o diagnóstico da LEB e de dois leucogramas com intervalo de 90 dias, somando-se três desvios padrão à contagem absoluta de linfócitos, segundo valores de referência. ${ }^{23}$ Os bovinos, então, foram agrupados em animais com sorodiagnóstico negativo (Grupo SN), animais com sorodiagnóstico positivo, porém alinfocitóticos (Grupo AL) e animais com sorodiagnóstico positivo apresentando LP (Grupo LP).

Cinco animais pertencentes a cada grupo foram selecionados, aleatoriamente, para a avaliação da fagocitose in vitro de $\mathrm{Sa}$ IP por leucócitos circulantes. Para tal, foi colhida, de cada animal, por venopunção coccígea, uma amostra em tubo siliconizado com heparina, que foi identificada e transportada, sob refrigeração, até o Laboratório de Imunodiagnóstico do Departamento de Clínica Médica da Faculdade de Medicina Veterinária e Zootecnia da Universidade de São Paulo.

Para cada amostra, dois tubos para citometria foram identificados. Neles, foi 
adicionado $100 \mu \mathrm{L}$ de sangue e, em um tubo de cada animal, foi acrescentado $100 \mu \mathrm{L}$ de Sa-IP [Staphylococcus aureus (cepa ATCC 25923) conjugado com iodeto de propídio $\left(\right.$ Sigma $^{\mathrm{TM}}$, St. Louis, MO; ${ }^{\circ}$. cat. P4170)]. Em todas alíquotas, foi adicionado PBS gelado, em quantidade suficiente para um volume total de 1,1 mL. Os tubos foram, então, incubados em banho-maria, a uma temperatura de $37^{\circ} \mathrm{C}$, sob agitação ligeira. Depois de 30 minutos de incubação, foi adicionado $2 \mathrm{~mL}$ de solução gelada de EDTA a $3 \mathrm{mM}$, para o bloqueio das reações. A seguir, foram centrifugados por 10 minutos, a 400 g. Para a lise dos eritrócitos, após desprezar-se o sobrenadante, foi colocado $2 \mathrm{~mL}$ de $\mathrm{NaCl}$ a $0,2 \%$ e, esperados 20 segundos, $2 \mathrm{~mL}$ de $\mathrm{NaCl}$ a 1,6\%, para a recomposição da isotonicidade. Repetiu-se a lise de eritrócitos e, após desprezar-se o sobrenadante mais uma vez, em cada tubo foi adicionado $500 \mu \mathrm{L}$ de PBS gelado.

As amostras assim preparadas foram, então, levadas imediatamente ao Laboratório de Técnicas Imunológicas Aplicadas à Morfofisiologia do Departamento de Cirurgia ou ao Laboratório de Neuroiminomodulação do Departamento de Patologia, ambos da Faculdade de Medicina Veterinária e Zootecnia da Universidade de São Paulo, para serem avaliadas em citômetros de fluxo FACSCalibur (Becton Dickinson Immunocytometry System $^{\mathrm{TM}}$, San Diego, CA). Dez mil eventos de cada amostra foram adquiridos e analisados por meio do programa Cell Quest Pro (Becton Dickinson Immunocytometry System ${ }^{\mathrm{TM}}$, San Diego, CA). A quantificação da capacidade de fagocitose foi feita pela intensidade média da fluorescência emitida por célula e a porcentagem de leucócitos realizando fagocitose foi calculada a partir do número de leucócitos emitindo fluorescência, dividido pelo número total de leucócitos por ensaio, multiplicados por 100. Para tal, foi utilizado o programa Flowjo (Tree Star ${ }^{\mathrm{TM}}$, Inc., Ashland, OR), versão 7.1.3.

Conforme indicado por CallegariJacques $^{24}$, foi verificada a normalidade da distribuição dos resultados, utilizando-se do teste de Anderson-Darling, e sua homoscedasticidade, utilizando-se do teste F (para dados que apresentaram distribuição normal) ou do teste de Lavene (para dados que não apresentaram distribuição normal).

Para a análise das freqüências observadas, foi utilizado o teste Quiquadrado. Para a avaliação das diferenças entre as médias dos resultados obtidos, foram feitos os testes de análise de variância (One-way ANOVA) e de Tukey-Kramer ou o teste $\mathrm{t}$ (para dados com distribuição normal), e de Mann-Whitney ou de KruskalWallis (para dados que não apresentaram distribuição normal). Para todos os resultados, foram consideradas significantes as análises que apresentaram pd"0,05. Nas avaliações estatísticas, foi utilizado o software estatístico MINITAB (GlobalTech Informática $^{\mathrm{TM}}$, Belo Horizonte, $\mathrm{MG}$ ), versão 14.1.

\section{Resultados e Discussão}

Foi avaliada a influência da infecção pelo VLB na atividade fagocítica in vitro de leucócitos bovinos na fase alinfocitótica da enfermidade e na presença de LP utilizandose da análise por citometria de fluxo, que, neste contexto, mostrou ser uma técnica célere, que demandou pequeno volume sangüíneo e eliminou a necessidade de prévia separação das populações leucocitárias, conforme destacado por Vowells et al. ${ }^{25}$.

Das 99 vacas triadas, $62(62,63 \%)$ foram classificadas como pertencentes ao Grupo SN; 30 (30,30\%), pertencendo ao Grupo AL; e 7 (7,07\%), constituindo o Grupo LP (Figura 1). Tal incidência assemelha-se àquela verificada por Olson et al. ${ }^{26}$, que observaram incidências variando entre $24 \%$ e $42 \%$ em rebanhos leiteiros na Alemanha, e àquelas observadas em diversos levantamentos sorodiagnósticos realizados em rebanhos leiteiros brasileiros ${ }^{27}$, nos quais as taxas de incidência oscilavam entre $20,7 \%$ e $53,3 \%$.

$\mathrm{Na}$ avaliação da fagocitose in vitro de Sa-IP, verificou-se que, entre as amostras 


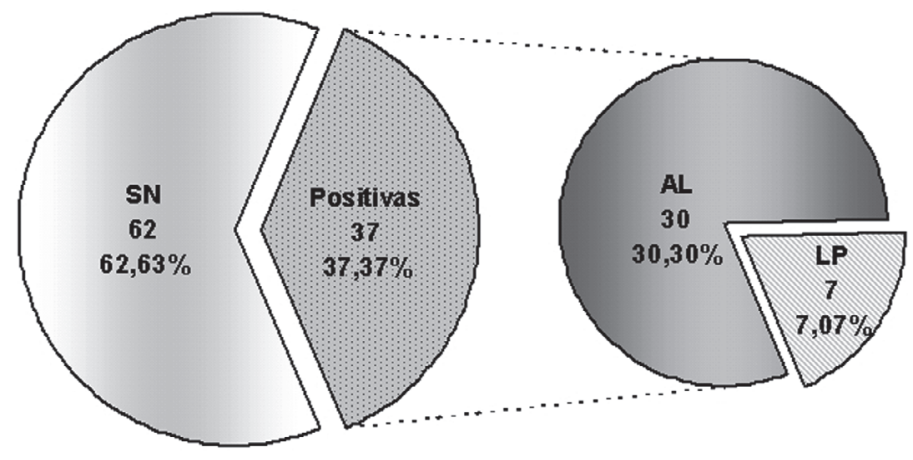

\section{$\square \mathrm{SN}$ : vacas soronegatitivas \\ 口AL: vacas soropositivas alinfocitóticas \\ $\square$ LP: vacas soropositivas com linfocitose persistente}

Figura 1 - Distribuição de 99 vacas da raça Holandês Preto e Branco, em função dos resultados da imunodifusão em gel de agar (IDAG) para diagnóstico de leucose enzoótica bovina e do leucograma - São Paulo - 2007

sangüíneas dos animais do Grupo SN, a porcentagem média de células realizando fagocitose não diferiu da média observada entre as amostras sangüíneas dos animais do Grupo AL. Contudo, ambas foram maiores $(p=0,047)$ que aquela verificada entre as amostras sangüíneas dos animais do Grupo LP (Figura 2).
Observou-se, também, que a intensidade média de fluorescência do iodeto de propídio (em unidades arbitrárias) nos leucócitos que estavam fagocitando, entre as células obtidas de animais pertencentes ao Grupo LP foi menor $(p<0,001)$ que aquela observada entre as células de animais pertencentes ao Grupo AL, e que aquela

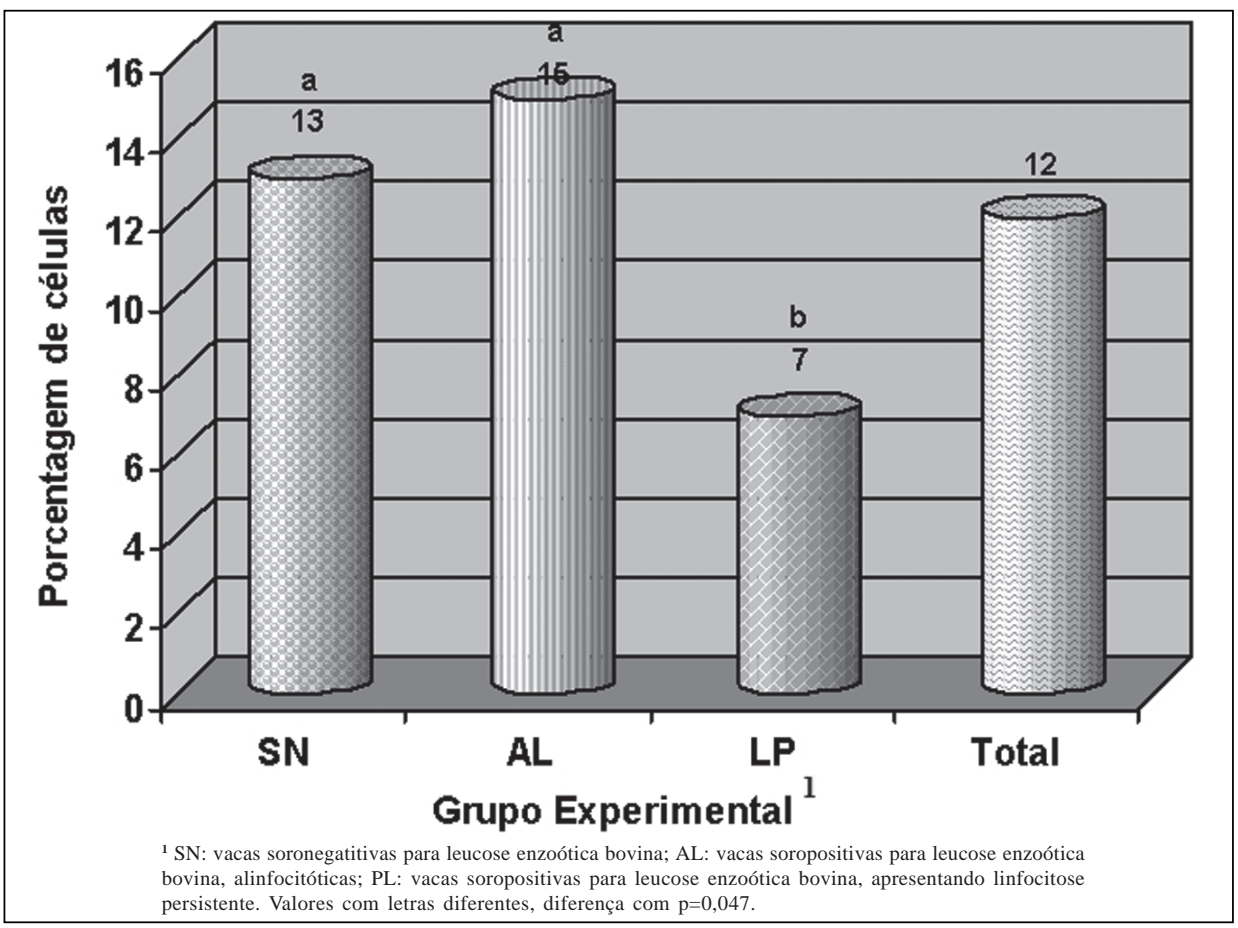

Figura 2 - Porcentagem de leucócitos fagocitando Staphylococcus aureus, avaliada por citometria de fluxo, em amostras sangüíneas de 15 vacas da raça Holandês Preto e Branco, em relação ao grupo experimental - São Paulo - 2007 
observada entre as células de animais pertencentes ao Grupo SN (Figura 3).

Tais resultados permitem-nos suscitar que animais manifestando LP apresentam uma menor porcentagem de leucócitos realizando fagocitose, fato que pode ser explicado por uma maior quantidade relativa de linfócitos. No entanto, fagócitos sangüíneos obtidos de animais com LP fagocitam menos, apontando a influência das alterações que induzem à LP na capacidade fagocítica dos leucócitos.

No estudo de Kaczmarczyk, Bojarojc-Nosowicz e Fiedorowicz ${ }^{28}$, em que a atividade de fagócitos foi avaliada por meio do teste de redução do NBT, não foi encontrada diferença na eficiência metabólica de fagócitos obtidos de animais soropositivos ou de animais soronegativos para LEB. Entretanto, um prévio diagnóstico diferencial entre animais manifestando LP e animais alinfocitóticos nesse estudo, poderia conduzir a resultados semelhantes aos encontrados no presente trabalho.

Por outro lado, os resultados corroboram com aqueles verificados por Werling et al. ${ }^{29}$, que observaram que havia uma menor porcentagem de monócitos realizando fagocitose e que os monócitos obtidos de animais soropositivos apresentaram menor atividade fagocítica que células colhidas de animais soronegativos. Porém, convém observar que, segundo Smitts, Burvenich e Heyneman ${ }^{16}$, em ensaios em que se visa mensurar a fagocitose, a incubação de bactérias com o sangue total (em oposição à incubação com populações de leucócitos previamente separadas) reflete a combinação da capacidade fagocítica dos fagócitos com a atividade opsonizante do plasma. Também neste estudo, os autores não verificaram a presença de LP, fato que não permite apontar se tais observações ocorreram apenas em células obtidas de animais nesta fase da infecção.

Os estudos conduzidos por Pyeon, O'Reilly e Splitter ${ }^{30}$ e, posteriormente, por Yakobson et al..$^{31}$, Amills et al..$^{32}$, Debacq et al. ${ }^{33}$ e Konnai et al. ${ }^{34,35}$ sugerem que uma alteração no perfil de citocinas envolvidas

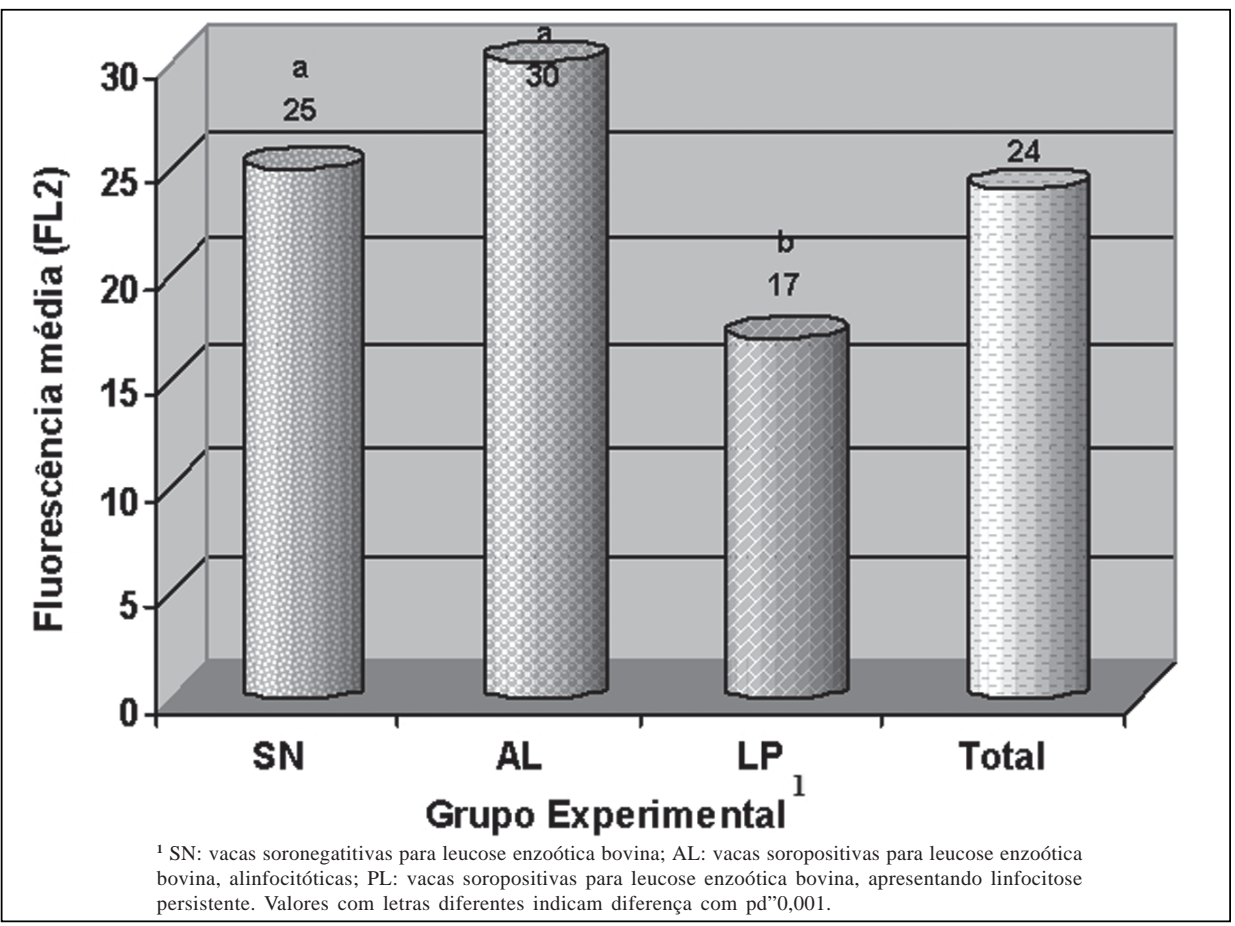

Figura 3 - Intensidade de fagocitose de Staphylococcus aureus (em valores arbitrários de fluorescência do iodeto de propídio), verificada em leucócitos de amostras sangüíneas de 15 vacas da raça Holandês Preto e Branco, em relação ao grupo experimental - São Paulo - 2007 
na resposta imune celular (Th-1) para aquele encontrado na resposta humoral (Th-2) possa estar envolvida com a progressão da enfermidade para as fases de LP ou de linfossarcoma. Mormente, uma maior produção de TNF-á e o desbalanço na expressão de receptores celulares de TNF, observados por Kabeya, Ohashi e Onuma ${ }^{36}$, pode induzir à maior sobrevivência dos linfócitos $\mathrm{B}$, quer aumentando sua taxa de proliferação, quer diminuindo seu índice de apoptose, e, deste modo, conduzir o hospedeiro ao status de LP.

Não obstante, tal alteração no perfil de citocinas durante fase de LP, possivelmente, interfere na atividade de outras populações celulares relacionadas ao sistema imunológico. Em especial, a menor produção de IFN-ã verificada em animais manifestando LP observada por Keefe et al. ${ }^{37}$ e confirmada por Amills et al..$^{32}$ pode ser a responsável pela alteração da atividade fagocítica de leucócitos observada no presente trabalho.

A proteção provida pelos mecanismos imunológicos inatos é crucial na defesa contra doenças infecciosas. Para tanto, células utilizam-se, primordialmente, da fagocitose e de atividades dependentes e não-dependentes de oxigênio ${ }^{38}$. Com a crescente preocupação acerca das imunodeficiências primárias e secundárias, pesquisadores têm empregado métodos diversos na avaliação da resposta imunológica, tanto em humanos, quanto em diferentes espécies animais. Nestes, a quantificação da atividade fagocítica foi realizada por Szejda et al. ${ }^{14}$, por Flaminio et al. ${ }^{22}$ e Massoco e Palermo Neto ${ }^{21}$.

Por sua vez, estudos acerca dos mecanismos patogênicos do VLB fornecem informações para a elucidação das interações entre os demais Deltaretrovírus e seus hospedeiros. No entanto pesquisas abrangendo a LEB são pautadas, primordialmente, nos aspectos econômicos da enfermidade, nos meios diagnósticos, nos levantamentos epidemiológicos (sorológicos e, ultimamente, genéticos), nos modos de transmissão e em programas de controle. Entretanto, os resultados observados no presente trabalho indicam que alterações que induzem à persistência da linfocitose, na infecção pelo VLB, quer pela influência direta da atividade proviral, quer por meio de atividade secundária à alteração quantitativa e/ou qualitativa de citocinas, podem induzir o animal a um estado imunossupressivo.

\section{Conclusão}

Os resultados verificados no presente trabalho permitem-nos inferir que animais infectados pelo VLB, manifestando LP, apresentam leucócitos circulantes com função fagocítica reduzida.

\section{Influence of Enzootic Bovine Leukosis on phagocytic function of circulating leukocytes from animals with persistent lymphocytosis}

\begin{abstract}
This study evaluated the phagocytosis of propidium iodide-labeled Staphylococcus aureus (PI-Sa) by circulating leukocytes obtained from five Enzootic Bovine Leukosis (EBL)-negative cows, five naturally EBL-infected, non-lymphocytotic cows, and five EBL-positive cows with persistent lymphocytosis (PL), analyzed by flow cytometry. Among cells obtained from EBL-infected cows, presenting PL, the percentage of leukocytes carrying out phagocytosis $(7.20 \%)$, was smaller $(\mathrm{p}=0.047)$ than that verified among cells obtained from non-infected $(12.90 \%)$, and from BLV-infected, non-lymphocytotic cows (14.70\%). Furthermore, leukocytes obtained from EBL-infected cows, presenting PL, showed smaller phagocytosis intensity (characterized by the intensity of propidium iodide fluorescence) than leukocytes obtained
\end{abstract}

\author{
Key words: \\ Bovine. \\ Leukocytes. \\ Phagocytosis. \\ Enzootic Bovine Leukosis. \\ Flow Cytometry.
}


from non-infected and from EBL-infected, non-lymphocytotic, cows $(\mathrm{p}<0.001)$. Therefore, results show a decreased phagocytic function among circulating leukocytes obtained from BLV-infected, lymphocytotic cows.

\section{Referências}

1 SCHWARTZ, I.; LEVY, D. Pathobiology of bovine leukemia virus. The Veterinary Research, v. 25, n. 6, p. 521-536, 1994.

2 SAGATA, N.; IKAWA, Y. BLV and HTLV-I: their unique genomic structures and evolutionary relationship. Princess Takamatsu Symposia, v. 15, p. 229-240, 1984.

3 SAGATA, N.; YASUNAGA, T.; TSUZUKUKAWAMURA, J.; OHISHI, K.; OGAWA, Y.; IKAWA, $Y$. Complete nucleotide sequence of the genome of bovine leukemia virus: its evolutionary relationship to other retroviruses. Proceedings of the National Academy of Sciences of the United States of America, v. 82, n. 3 , p. $677-681,1985$

4 PARODI, A. L. Pathology of enzootic bovine leukosis: comparision with the sporadic form. In: BURNY, A.; MAMMERICKX, M. (Ed.). Enzootic bovine leukosis and bovine leukemia virus. Boston: Martinus Nijhoff, 1987. p. 15-49.

5 THURMOND, M. C. Economics of enzootic bovine leukosis. In: BURNY, A.; MAMMERICKX, M. (Ed.). Enzootic bovine leukosis and bovine leukemia virus. Boston: Martinus Nijhoff, 1987. p. 71-83.

6 THURMOND, M. C.; LAPUZ, G. R.; FARVER, T. B.; MANDAC, G. C. Retrospective study of four years of carcass condemnation rates for malignant lymphoma in California cows. American Journal of Veterinary Research, v. 46, n. 6, p. 1387-1391, 1985.

$7 \mathrm{CHI}$, J.; VANLEEUWEN, J. A.; WEERSINK, A.; KEEFE, G. P. Direct production losses and treatment costs from bovine viral diarrhea virus, bovine leukosis virus, Mycobacterium avium subspecies paratuberculosis, and Neospora caninum. Preventive Veterinary Medicine, v. 55, n. 2 , p. 137-153, 2002

8 OTT, S. L.; JOHNSON, R.; WELLS, S. J. Association between bovine-leukosis virus seroprevalence and herdlevel productivity on US dairy farms. Preventive Veterinary Medicine, v. 61, n. 4, p. 249-262, 2003.

9 RHODES, J. K.; PELZER, K. D.; JOHNSON, Y. J. Economic implications of bovine leukemia virus infection in mid-Atlantic dairy herds. Journal of American Veterinary Medical Association, v. 223, n. 3, p. 346-352, 2003.

10 RHODES, J. K.; PELZER, K. D.; JOHNSON, Y. J.; RUSSEK-COHEN, E. Comparison of culling rates among dairy cows grouped on the basis of serologic status for bovine leukemia virus. Journal of American Veterinary Medical Association, v. 223, n. 2, p. 229-231, 2003.
11 SCHWARTZ, I.; BENSAID, A.; POLACK, B.; PERRIN, B.; BERTHELEMY, M.; LEVY, D. In vivo leukocyte tropism of bovine leukemia virus in sheep and cattle. Journal of Virology, v. 68, n. 7, p. 45894596, 1994

12 YIN, S.; MAKARA, M.; PAN, Y.; ISHIGURO, H.; IKEDA, M.; NUMAKUNAI, S.; GORYO, M.; OKADA, $K$. Relation between phenotype of tumor cells and clinicopathology in bovine leukosis. Journal of Veterinary Medical Science, v. 65, n. 5, p. 599-606, 2003.

13 VERHOEF, J.; WALDVOGEL, F. A. Testing phagocytic cell function. European Journal of Clinical Microbiology, v. 4, n. 4, p. 379-391, 1985.

14 SZEJDA, P.; PARCE, J. W.; SEEDS, M. S.; BASS, D. A. Flow cytometric quantitation of oxidative product formation by polymorphonuclear leukocytes during phagocytosis. Journal of Immunology, v. 133, n. 6, p. 3303-3307, 1984.

15 VAN OOSTVELDT, K.; PAAPE, M. J.; DOSOGNE, H.; BURVENICH, C. Effect of apoptosis on phagocytosis, respiratory burst and CD18 adhesion receptor expression of bovine neutrophils. Domestic Animal Endocrinology, v. 22 , n. 1, p. 37-50, 2002.

16 SMITS, E.; BURVENICH, C.; HEYNEMAN, R. Simultaneous flow cytometric measurement of phagocytotic and oxidative burst activity of polymorphonuclear leukocytes in whole bovine blood. Veterinary Immunology and Immunopathology, v. 56 , n. 3-4, p. 259-269, 1997.

17 KAMPEM, A. H.; TOLLERSRUD, T.; LARSEN, S.; ROTH, J. A.; FRANK, D. E.; LUND, A. Repeatability of flow cytometric and classical measurement of phagocytosis and respiratory burst in bovine polymorphonuclear leukocytes. Veterinary Immunology and Immunopathology, v. 97, n. 1-2, p. 105-114, 2004.

18 KAMPEM, A. H.; TOLLERSRUD, T.; LUND, A. Flow cytometric measurement of neutrophil respiratory burst in whole bovine blood using live Staphylococcus aureus. Journal of Immunological Methods, v. 289, n. 1-2, p. 47-55, 2004.

19 SILVEIRA, L. R. Considerações críticas e metodológicas na determinação de espécies reativas de oxigênio e nitrogênio em células musculares durante contrações. Arquivos Brasileiros de Endocrinologia e Metabologia, v. 48, n. 6, p. 812-822, 2004.

$20 \mathrm{SOH}, \mathrm{N}$. Recent advances in fluorescent probes for the detection of reactive oxygen species. Analytical and Bioanalytical Chemistry, v. 386, n. 3, p. 532-543, 2006.

21 MASSOCO, C.; PALERMO NETO, J. Effects of 
midazolan on equine innate immune response: a flow cytometric study. Veterinary Immunology and Immunopathology, v. 95, n. 1-2, p. 11-19, 2003.

22 FLAMINIO, M. J. B. F.; RUSH, B. R.; DAVIS, E. G.; HENNESSY, K.; SHUMAN, W.; WILKERSON, M. J. Simultaneous flow cytometric analysis of phagocytosis and oxidative burst activity in equine leukocytes. Veterinary Research Communications, v. 26, n. 2, p. 85-92, 2002.

23 TAVORA, J. P. F. Hemograma de bovinos das raças Gir, Girolando e Holandesa criados no Estado de São Paulo: estabelecimento dos valores de referência e avaliação das influências de fatores de variabilidade raciais, etários e sexuais. 1997. 163 f. Tese (Doutorado em Clínica Veterinária) - Faculdade de Medicina Veterinária e Zootecnia, Universidade de São Paulo, São Paulo, 1998.

24 CALLEGARI-JACQUES, S. M. Bioestatística: princípios e aplicações. Porto Alegre: ARTMED, 2003. $256 \mathrm{p}$.

25 VOWELLS, S. J.; SEKHSARIA, S.; MALECH, H. L.; SHALIT, M.; FLEISHER, T. A. Flow cytometric analysis of the granulocyte respiratory burst: a comparison study of fluorescent probes. Journal of Immunological Methods, v. 178, n. 1, p. 89-97, 1995.

26 OLSON, C.; HOSS, H. E.; MILLER, J. M.; BAUMGARTENER, L. E. Evidence of bovine C-type (leukemia) virus in dairy cattle. Journal of the American Veterinary Medical Association, v. 163, n. 4, p. 355357, 1973.

27 LORENZ, R. J.; STRAUB, O. C. The epidemiology of enzootic bovine leukosis. In: BURNY, A.; MAMMERICKX, M. (Ed.). Enzootic bovine leukosis and bovine leukemia virus. Boston: Martinus Nijhoff, 1987. p. 51-68.

28 KACZMARCZYK, E.; BOJAROJC-NOSOWICZ, B.; FIEDOROWICZ, A. Leukocyte acid phosphatase and metabolic efficiency of phagocytes in the first lactation trimester of cows from a leukaemic herd. Journal of Applied Genetics, v. 46, n. 1, p. 59-67, 2005.

29 WERLING, D.; HOWARD, C. J.; NIEDERER, E.; STRAUB, O. C.; SAALMULLER, A.; LANGHANS, W. Analysis of the phenotype and phagocytic activity of monocytes/macrophages from cattle infected with the bovine leukaemia virus. Veterinary Immunology and Immunopathology, v. 62, n. 3, p.
185-195, 1998.

30 PYEON, D.; O'REILLY, K. L.; SPLITTER, G. A. Increased interleukin-10 mRNA expression in tumorbearing or persistently lymphocytotic animals infected with bovine leukemia virus. Journal of Virology, v. 70, n. 8, p. 5706-5710, 1996.

31 YAKOBSON, B.; BRENNER, J.; UNGAR-WARON, H.; TRAININ, Z. Cellular immune response cytokine expression during the initial stage of bovine leukemia virus (BLV) infection determines the disease progression to persistent lymphocytosis. Comparative Immunology, Microbiology and Infectious Diseases, v. 23, n. 3, p. 197-208, 2000.

32 AMILLS, M.; RAMIYA, V.; NORIMINE, J.; OLMSTEAD, C. A.; LEWIN, H. A. Reduced IL-2 and IL4 mRNA expression in CD4 + T cells from bovine leukemia virus-infected cows with persistent lymphocytosis. Virology, v. 304, n. 1, p. 1-9, 2002.

33 DEBACQ, C.; ASQUITH, B.; REICHERT, M.; BURNY, A.; KETTMANN, R.; WILLEMS, L. Reduced cell turnover in bovine leukemia virus-infected, persistently lymphocytotic cattle. Journal of Virology, v. 77, n. 24, p. 13073-13083, 2003.

34 KONNAI, S.; USUI, T.; IKEDA, M.; KOHARA, J.; HIRATA, T.; OKADA, K.; OHASHI, K.; ONUMA, M. Imbalance of tumor necrosis factor receptors during progression in bovine leukemia virus infection. Virology, v. 339, n. 2, p. 239-248, 2005.

35 KONNAI, S.; USUI, T.; IKEDA, M.; KOHARA, J.; HIRATA, T.; OKADA, K.; OHASHI, K.; ONUMA, M. Tumor necrosis factor-alpha up-regulation in spontaneously proliferating cells derived from bovine leukemia virus-infected cattle. Archives of Virology, v. 151, n. 2, p. 347-360, 2006

36 KABEYA, H.; OHASHI, K.; ONUMA, M. Host immune responses in the course of bovine leukemia virus infection. Journal of Veterinary Medical Science, v. 63, n. 7, p. 703-708, 2001.

37 KEEFE, R. G.; CHOI, Y.; FERRICK, D. A.; STOTT, J. L. Bovine cytokine expression during different phases of bovine leukemia virus infection. Veterinary Immunology and Immunopathology, v. 56, n. 1-2, p. 39-51, 1997.

38 ALBERTS, B.; JOHNSON, A.; LEWIS, J.; RAFF, M.; ROBERTS, K.; WALTER, P. Molecular biology of the cell. 4. ed. New York: Garland, 2002. 1616 p. 